\title{
Economics of controlling avian influenza epidemics
}

\author{
M.A.P.M. van Asseldonk ${ }^{\#}$ M.P.M. Meuwissen ${ }^{\#}$, M.C.M. Mourits ${ }^{\#}$ and \\ R.B.M. Huirne
}

\begin{abstract}
Livestock epidemics like avian influenza (AI) may inevitably affect many farms at the same time, causing severe economic losses for governments, farmers and all other participants of the poultry production chain. This paper gives an overview of the various economic consequences incurred by AI epidemics. The funding of these losses is discussed, making a distinction between the compensation currently regulated by the EU or national government and the additional financing possibilities by means of insurance or co-financing systems. A general economic analysis is performed to explore the required level of insurance or co-financing rates for the various EU member states to cover the expected AI losses. The level of rates turned out to vary widely among the individual EU countries.

Keywords: contagious animal diseases; avian influenza; economic consequences; compensation; EU; direct losses; consequential losses; co-financing levy; insurance premium
\end{abstract}

\section{Introduction}

The European Union (EU) aims at assuring a high level of animal health and animal welfare without compromising the functioning of the internal market (Mission Statement DG Health and Consumer Protection, Homepage DG SANCO). To achieve this goal the EU follows a strategy of non-vaccination for most highly contagious animal diseases. To control possible outbreaks, the EU member states have adopted regular control measures, consisting of stamping out of infected herds, pre-emptive slaughter of contact herds, and the establishment of protection $(>3 \mathrm{~km})$ and surveillance $(>10 \mathrm{~km})$ zones.

During the last decade, a number of large outbreaks of contagious livestock diseases occurred throughout the EU, including foot and mouth disease (FMD), classical swine fever (CSF) and highly pathogenic avian influenza (AI) (OIE classification of diseases: animal diseases data (website)). These had a devastating veterinary impact: FMD and CSF caused the slaughter of millions of cattle, sheep and pigs (OIE classification of diseases: animal diseases data (website)). For example, during the last epizootic of AI in The Netherlands, around 30 million animals were slaughtered, i.e., half of the Dutch poultry population (Homepage LNV). The economic losses due to FMD in the UK in 2001, to CSF in The Netherlands in 1997

\footnotetext{
\# Institute for Risk Management in Agriculture (IRMA), Wageningen University, Hollandseweg 1, $6707 \mathrm{KN}$ Wageningen, The Netherlands

\# Business Economics, Wageningen University, Hollandseweg 1, $6706 \mathrm{KN}$ Wageningen, The Netherlands
} 
and to AI in Italy in 1999-2000 were estimated at 12,500 million Euro, 2,300 mEuro and 500 mEuro, respectively. These figures demonstrate that the economic consequences of highly contagious animal diseases can be enormous.

This paper gives an overview of the various economic consequences incurred by contagious animal disease in general and AI in particular. Subsequently, the funding of these losses is discussed, making a distinction between the compensation currently regulated by the EU and the additional financing possibilities by means of insurance or co-financing systems.

Estimating the insurance premium or a co-financing levy is very complicated. In the final part of the paper a general economic analysis is introduced to explore the required level of insurance or co-financing rates for the various EU member states to cover the losses of an AI outbreak.

\section{Control measures to contain avian influenza outbreaks in the EU}

Within the EU, measures to control and eradicate AI have been harmonized by EU legislation (Directive 92/40/EEC). All suspected cases of AI within EU member states must be investigated, while appropriate measures are taken in case of confirmation of highly pathogenic AI. To limit the spread, infected poultry must be killed in a humane way and disposed of safely. Feeding stuffs, contaminated equipment and manure must be destroyed or treated to inactivate the virus.

To prevent further spread of disease the veterinary authorities are required to put in place movement restrictions immediately on the affected holdings and on all farms in a radius of at least $10 \mathrm{~km}$ around these holdings, the so-called surveillance zone. If necessary, stamping-out measures can also be extended to poultry farms in the vicinity of, or which have had dangerous contacts with, infected farms (pre-emptive slaughter).

In accordance with EU legislation, all member states have AI contingency plans in place to ensure that the most appropriate measures are immediately implemented. Depending on the severity of the epidemic, national governments can take additional control measures, such as the pre-emptive slaughter of all flocks within a certain radius of infected and detected flocks. During the 2003 AI epidemic in The Netherlands, the Dutch government decided, for instance, on a temporary nation-wide standstill for the transport of live poultry. Also, flocks within a 1-km radius of detected or suspected flocks were pre-emptively slaughtered. In a further stage of the epidemic this pre-emptive slaughter measure was even more intensified to create poultry-free buffer zones.

If movement restriction zones lead to severe animal welfare problems on the farms (e.g. farms with broilers), so-called welfare slaughter is generally applied. With stamping out and pre-emptive slaughter, buildings are completely emptied (i.e. depopulated). With welfare slaughter, buildings may only become partly empty. All animals in stamping-out, pre-emptive slaughter and welfare slaughter programmes are destroyed and rendered.

In accordance with Directive 92/40/EEC, emergency vaccination against AI may be used to supplement the control measures carried out after confirmation of the disease. Birds vaccinated against the subtype corresponding to the one which is circulating are protected against the worst effects of AI. 


\section{Economic losses caused by AI epidemics}

Economic losses incurred by epidemics of contagious livestock diseases like AI can be divided into various categories. An intuitive distinction can be made between direct losses and indirect or consequential losses. Direct losses refer to the costs of the execution of the eradication campaign reflected by, for instance, the value of destroyed animals and the costs of organizational aspects such as the monitoring of farms in restriction zones. Consequential losses are the 'long-term' consequences due to movement restrictions and market disruptions. They can be divided into five categories (see also Meuwissen et al. 1999):

(1) Business interruption: Business interruption occurs because farm buildings become (partly) empty due to stamping out, pre-emptive slaughter or welfare slaughter, and stay empty until movement restrictions are lifted. On farms that are empty, losses from business interruption can be limited by an alternative application of idle production factors; farmers can for instance renovate their stables, temporarily seek another job, etc.

(2) Losses related to established movement restriction zones: farms in movement restriction zones face (long) periods in which animals (such as broilers) and manure cannot be transported from the farm. These periods are characterized by animal welfare problems, extra feeding costs and emergency measures for storage of manure.

(3) Repopulation of the farm. These losses include losses due to extra weeks with empty buildings (for example because new layers are not readily available) and extra costs of animal health problems. These losses thus do not refer to the costs of buying a new flock; government compensation for the slaughtered flock is generally sufficient to buy back a flock of equal quality.

(4) Losses from emergency vaccination: given a situation in which vaccinated animals are destroyed, losses might arise from the above categories (business interruption, repopulation costs). However, for reasons of social acceptability, the rendering of vaccinated animals is under debate. With future epidemics, meat from vaccinated animals may be destined to the local market, which likely leads to extra costs and/or lower prices.

(5) Price effects. Livestock epidemics can have a rather severe impact on prices. The size and duration of the impact depends on aspects such as the size of the epidemic (duration, size of restricted area), reactions of other countries (closure of borders, increased production) and whether vaccination is applied (which generally leads to long periods of export limitations). Price effects depend to a large extent on the fact whether a country in which an outbreak occurs is an importing or exporting country with respect to products (e.g., eggs) involved in the export limitations. For exporting countries these price effects may result in enormous losses, exceeding the direct losses many times.

Note that other parts of the agricultural supply chain (e.g., breeding organizations, feed mills, slaughter houses, processing industry, transportation companies) are also affected economically (sometimes positively, mostly negatively). Furthermore, outbreaks of contagious animal diseases can also have serious effects on the other parts of the economy as a whole because of the side effects of disease control measures (e.g. tourism) and interactions between economic sectors (falling prices for livestock products favour consumers). These effects are not further discussed. 


\section{Compensation payments}

\section{Direct losses}

Governments (national and European) generally bear the largest part of the direct losses. The European Union compensates part of the direct losses incurred. The veterinary budget of the European Union refunds in most cases $50 \%$ of the costs of compulsory and pre-emptive slaughter, $70 \%$ of the costs of welfare slaughter, and $50 \%$ of the organizational costs. In case of an approved emergency vaccination programme, the EU also provides funding for vaccines and vaccination campaigns.

The national compensation strategy of direct costs varies among EU member states. While some members states finance the direct losses from the national budget (e.g., UK and Denmark), most member states have set up some form of statutory system to co-finance the direct losses (e.g., Germany and The Netherlands). These public-private co-financing schemes have a compulsory fund structure in which all farmers pay a levy. Risk financing by means of a levy system is based on pooling over time within the livestock sector. Payments to the fund can be organized through upfront payments (deposit) or through assessment payments after an epidemic, or both. However, most member states have opted for an assessment approach. These latter systems have no annually fixed levies. The government will finance the compensation payments in advance. The input of the government will however be repaid over the following years. Therefore, after an epidemic, the levy is set according to the amount that the government paid in advance for the sector. In an 'up-front' programme levies are deposited in a fund before an outbreak. However, the size of the payments (reservations) is uncertain and thus there is also the possibility that assessment payments will be necessary (Van Asseldonk, Meuwissen and Huirne 2004).

In case of co-financing to complement the public part, the amount that is financed by the sector can be proportional or non-proportional, or both. If risks are shared between the sector and the national government by means of a proportional contract (i.e., pro rata contract) the levy is specified as a fraction of the coverage. With nonproportional contracts, the national government indemnifies only claims in excess of a particular threshold.

In The Netherlands the current co-finance contract is based on a private bankguarantee system (i.e., an up-front levy system). The Dutch guarantee system is in the form of a non-proportional contract. Within the system the government can withdraw capital without prior approval of the farming sector from a private bank to (co-) finance actual losses. Any capital provided by the bank is paid back with interest by the primary sector through assessment payments over a certain time horizon.

The Dutch co-financing system became operational in 2000 by the establishment of the so-called 'National Animal Health Fund'. Individual farmers contribute to this fund by paying a fixed levy per animal or animal product. Adjustments of the levy could be made yearly, depending on the direct costs incurred by eradication in a particular year. Through this system of levies the Dutch poultry-farming sector (approx. 6400 commercial flocks) guarantees a maximal contribution to this fund of 11.3 million Euro in the five year period of 2000-2005. Similar agreements have been made with the pig and cattle sector, each accounting for a maximal contribution of 225 mEuro over the same time period. The Dutch government only compensates direct losses that exceed these predefined contributions, which was obviously the case with respect to the control costs of the 2003 AI epidemic. Total direct control costs of this epidemic equalled an amount of 270 mEuro (Homepage LNV). Based on the 
Dutch compensation system, these costs were covered for approximately $50 \%$ by the EU, $4 \%$ by the poultry industry and $46 \%$ by the Dutch government.

\section{Consequential losses}

The consequential (long-term) losses of the Dutch 2003 AI epidemic are expected to exceed three to four times the direct costs as a result of the serious disruption of production capacity (i.e. half of the poultry population was (pre-emptively) slaughtered) and of the Dutch export markets (Tacken et al. 2003). However, with respect to these consequential losses there is no financial compensation of the European or national government. These losses are completely borne by the farmers and other participants of the Dutch production chain involved.

Only a limited number of EU member states apply free public disaster assistance or compensate above the value of the animals that are compulsorily culled to cover part of the consequential losses. Public-private partnerships in the sense that national governments subsidize a consequential-loss policy are scarce. Insurance schemes could, therefore, be considered a relevant compensation option for consequential losses. A standard insurance scheme is financed through fixed advance payments (e.g., premiums). Insurance capacity is provided through various layers of own retention and reinsurance. However, in the case of an assessment mutual, the company has the right to assess their clients for losses and expenses via initial premiums or after a loss occurs (additional premiums) or both.

Few private insurance schemes exist on the European market to cover the risk of consequential losses as a result of epidemics in livestock. Those that do exist are either extensions of general livestock insurance policies or specific policies of stock insurers and mutual insurers. Many standard livestock insurance policies in Europe indemnify farmers for animal losses as a result of illness and accidents, but some have been extended, sometimes as an option, to cover at least part of the consequential losses from animal disease epidemics (Van Asseldonk, Meuwissen and Huirne 2004).

Premium or up-front levy setting (hence called rates) is very complicated and should be based on a profound knowledge of all factors included. With knowledge of the most important risk factors, the probability of an outbreak and its economic consequences, the level of the premium or levy can be estimated (Van Asseldonk, Meuwissen and Huirne 2004; Meuwissen, Van Asseldonk and Huirne 2003).

\section{Exploring the level of AI rates for various EU member states}

In this section the basis of a general economic analysis is introduced, by which the level of insurance premiums or co-finance levies for various EU members can be estimated. The economic analysis is based on expectations with respect to the potential spread of AI, by placing the consequences in the specific context of the country in which the outbreak might occur.

Such an analysis typically requires many epidemiological (e.g., disease spread, herd structure and animal intensity) and economic (e.g., income per animal, output prices, import/export position of country) data on the outbreak. In most countries, these basic data are not available. Therefore, a questionnaire was developed to collect these required data on introduction and spread by means of expert elicitation. The questionnaire was sent in 2002 to the Chief Veterinary Officers (CVOs) of the member states of the regional Commission Europe of the OIE. The subjective responses of the CVOs were used to provide a first insight into economic consequences of AI epidemics in the participating countries. 
The following countries participated in the study: Austria, Belgium, Cyprus, Czech Republic, Estonia, Finland, France, Germany, Greece, Hungary, Ireland, Israel, Italy, Latvia, Luxembourg, The Netherlands, Norway, Portugal, Turkey, Ukraine and United Kingdom (Wilpshaar et al. 2002).

\section{The questionnaire: Eliciting expert opinions on AI epidemics per country}

Historical data about the chance of introduction of AI are very limited in most countries. Since outbreaks of AI occur irregularly in time and place it is difficult to derive general properties and predictive values. Also the probability distribution describing the possible spread is difficult to ascertain. Because of this lack of data availability, the analysis used in this research is based on elicited subjective expert knowledge. Tree-point estimates that completely specify the so-called triangular probability distribution (asking for minimum, most likely and maximum values) were elicited to derive information concerning the chance of an outbreak, the number of infected farms, duration and radius of restriction zones. Solely on the basis of these numbers an estimation of the outbreak can be calculated (Van Asseldonk, Meuwissen and Huirne 2004).

As explained before, the above data for this research were collected by a questionnaire that was sent to all CVOs of the European member states of the OIE. The response rate was about $44 \%$ (i.e. 21 questionnaires). Thirty-six per cent of the returned questionnaires (i.e., 7 questionnaires) could not be used for the analysis because they were only partly completed and therefore not useful for calculations. So, consequently, the questionnaires of 14 countries were used in the final analysis.

\section{Monte Carlo simulation}

A Monte Carlo simulation model is constructed in order to obtain insight into the annual-loss distribution (Hardaker, Huirne and Anderson 1997). Monte Carlo simulation is considered an appropriate and very flexible method to investigate aspects that are stochastic of nature, such as livestock epidemics. Including the possibility of these types of events in a simulation model is an important technique in risk analysis. Risks are thereby incorporated as probability distributions. In this study, the problem situation is analysed by creating a stochastic simulation model, which is manipulated by input modification with respect to the different scenarios or decisions. The applied sampling technique is Monte Carlo sampling in which random numbers are sampled from a priori specified distributions, i.e. stochastic simulation. At each iteration, randomly drawn numbers from specified distributions are used representing a possible combination of values that could occur. Combining the results of each iteration will lead to a distribution of output values, reflecting a realistic aspect of chance.

In the Monte Carlo simulation model, a Poisson distribution reflects the uncertainty about the introduction of an epidemic in a specific year. Epidemic and ultimately economic consequences are reflected by triangular distributions, with parameters referring to the most likely, minimum and maximum values derived from the experts through the questionnaire. Results are based on 5000 iterations.

For calculating the economic consequences the following additional assumptions had to be made:

(1) For each infected farm, three farms are slaughtered pre-emptively.

(2) All affected farms (i.e. all farms that are infected, pre-emptively slaughtered and/or located in a restriction zone) face restrictions for the whole duration of the 
epidemic (i.e., there are no temporarily removals of restrictions for part of the farms).

More details of the epidemiological and economic models used for our analyses are published by Horst et al. (1999) and Meuwissen et al. (1997; 2003).

\section{Economic analysis based on questionnaire results}

The CVOs were asked about the expected occurrence and size of AI epidemics in their country for the next five years (i.e., 2003 - 2008). Table 1 shows the averages of the most likely, minimum and maximum estimated values of the occurrence of an outbreak (using all 14 questionnaires). It also shows the two extreme estimations, referred to as 'optimistic' and 'pessimistic'. As demonstrated by Table 1, AI is expected most likely to occur, on average, 0.86 times per country in the next 5 years. Of the 14 surveyed countries, the most optimistic individual-country estimation corresponded with the most likely, minimum and maximum number of outbreaks in 5 years of 0,0 and 1 , respectively. The country with the most pessimistic estimation reflected a most likely, minimum and maximum number of outbreaks of (respectively) 2, 0 and 5 (Table 1) in 5 years.

Table 1. Expected number of AI outbreaks per country for the years 2003 - 2008

\begin{tabular}{lccc}
\hline & $\begin{array}{c}\text { Most likely } \\
\text { (all countries; } \mathrm{n}=14)\end{array}$ & $\begin{array}{c}\text { Optimistic } \\
(\mathrm{n}=1)\end{array}$ & $\begin{array}{c}\text { Pessimistic } \\
(\mathrm{n}=1)\end{array}$ \\
\hline AI most likely & 0.86 & 0 & 2 \\
AI minimum & 0.23 & 0 & 0 \\
AI maximum & 3.08 & 1 & 5 \\
\hline
\end{tabular}

In Table 2 the most likely, minimum and maximum estimations for the size of AI epidemics are shown. Included were the number of farms infected, the duration of an epidemic (expressed in days) and the radius of restriction zones (in $\mathrm{km}$ ). The latter refers to the total area that is expected to be confronted with restrictive measures.

Table 2. Average expected size of AI epidemics for the period 2003-2008 and the most optimistic and most pessimistic individual scenarios (most likely values, and the minimum and maximum values between brackets)

\begin{tabular}{lccc}
\hline & $\begin{array}{c}\text { Most likely } \\
(\mathrm{n}=14)\end{array}$ & $\begin{array}{c}\text { Optimistic } \\
(\mathrm{n}=1)\end{array}$ & $\begin{array}{c}\text { Pessimistic } \\
(\mathrm{n}=1)\end{array}$ \\
\hline Number of poultry farms infected & $4(1-32)$ & $1(1-2)$ & $15(5-200)$ \\
Duration of epidemic (days) & $33(22-95)$ & $5(3-10)$ & $90(60-340)$ \\
Radius of affected area $(\mathrm{km})$ & $18(8-50)$ & $3(3-10)$ & $50(10-200)$ \\
\hline
\end{tabular}

The average most likely value of the number of farms that will be affected is 4 with a minimum of 1 and a maximum of 32 (during the 5-year period). The duration of the epidemic is estimated to last 33 days with a minimum of 22 days and a maximum of 95 days. The radius of the affected area is $18 \mathrm{~km}$ with a minimum of $8 \mathrm{~km}$ and a maximum of $50 \mathrm{~km}$. Again the most optimistic and most pessimistic estimated individual-country scenarios are shown (Table 2).

Direct and consequential losses are obtained by combining the epidemiological estimations of each country with the country-specific financial parameters. Table 3 shows the annual total-loss distributions (summation of direct losses and 
consequential losses) in million Euros, resulting from the simulation model for AI (5000 iterations). Data per epidemic are aggregated into annual data at the country level by considering the number of epidemics in a certain year and the losses per epidemic. (Countries are reported anonymously.)

Table 3. Total losses per country per year resulting from AI epidemics expressed in million euros and in per cent (\%) of the average animal value (average, 0.75 and 0.95 percentile (pc) values)

\begin{tabular}{ccccccc}
\hline Country & \multicolumn{3}{c}{ Million Euros } & \multicolumn{3}{c}{ Per cent of animal value } \\
\cline { 2 - 7 } & Average & $0.75 \mathrm{pc}$ & $0.95 \mathrm{pc}$ & Average & $0.75 \mathrm{pc}$ & $0.95 \mathrm{pc}$ \\
\hline $\mathrm{A}$ & 25.4 & 0.0 & 179.2 & 0.94 & 0.0 & 6.61 \\
$\mathrm{~B}$ & 11.6 & 0.0 & 2.4 & 19.46 & 0.0 & 3.94 \\
$\mathrm{C}$ & $0.0^{*}$ & 0.0 & 0.2 & 0.30 & 0.0 & 2.37 \\
$\mathrm{D}$ & 0.1 & 0.0 & 0.0 & 0.24 & 0.0 & 0.0 \\
$\mathrm{E}$ & 28.8 & 0.0 & 206.5 & 2.23 & 0.0 & 15.97 \\
F & $0.0^{*}$ & 0.0 & 0.2 & 0.15 & 0.0 & 1.03 \\
$\mathrm{G}$ & 0.1 & 0.2 & 0.4 & 0.09 & 0.16 & 0.38 \\
$\mathrm{H}$ & 1.5 & 2.8 & 6.5 & 0.44 & 0.82 & 1.92 \\
$\mathrm{I}$ & $0.0^{*}$ & 0.0 & $0.0^{*}$ & 0.02 & 0.0 & 0.08 \\
$\mathrm{~J}$ & $0.0^{*}$ & 0.0 & 0.0 & 0.08 & 0.0 & 0.0 \\
$\mathrm{~K}$ & $0.0^{*}$ & 0.0 & $0.0^{*}$ & 0.11 & 0.0 & 0.09 \\
$\mathrm{~L}$ & $0.0^{*}$ & 0.0 & 0.0 & 0.05 & 0.0 & 0.0 \\
M & 0.5 & 0.0 & 0.0 & 0.48 & 0.0 & 0.0 \\
$\mathrm{~N}$ & 47.0 & 0.0 & 345.0 & 8.40 & 0.0 & 61.71 \\
\hline
\end{tabular}

* Values are not exactly zero but decimals are not sufficient to represent

The results of Table 3 show that the average expected total losses for AI vary from almost $€ 0.0$ million (country C, F, I, J, K and L) to $€ 47.0$ million per year (country $\mathrm{N}$ ). The 0.75 and 0.95 percentile values indicate that the distributions of the annual total costs are skewed. The 0.75 percentile values demonstrate that - independent of the country surveyed - in 75 per cent of the cases, the estimated annual losses of an AI outbreak are less than $€ 3 \mathrm{mln}$. However, for the countries A, E and N, there is a $5 \%$ chance that these annual losses exceed $€ 100 \mathrm{mln}$ (see 0.95 percentile values).

Given the estimated loss distribution, including the part that is compensated by the EU, the level of insurance/co-finance rates can be evaluated. The estimated rates are expressed in per cent of the animal value. The spread in rates originates form the number and severity of epidemics occurring. The second part of Table 3 shows the annual distribution of these estimated rates. Again data are aggregated into annual data at country level by considering the number of epidemics in a certain year and the losses per epidemic.

The average expected total losses for AI per year vary from $0.02 \%$ of the (countryspecific) average poultry value (country I) to $19.46 \%$ (country B). The percentile values of the annual rates demonstrate, once more, a rather skewed distribution.

\section{Discussion and conclusion}

Poultry production regions can be divided on the basis of the degree of risk to experience an AI epidemic. A risk classification can be based on several criteria such as border regulations (e.g. sanitary controls, hygienic measures, number of live animal imports/exports), flock or animal density, and natural borders (rivers, mountains, 
seas). These criteria fluctuate widely across the surveyed countries, resulting in varying estimations with respect to the possible chance of an AI outbreak (Table 1) and subsequent epidemiological consequences (Table 2). Along with the export/import situation of a country, these variations result in substantial differences between the country-specific expected rates to cover the economic losses of an AI outbreak (Table 3).

These differences will complicate the formulation of a possible EU-wide insurance to cover the non-compensated part of the losses. A major problem in insuring losses from epidemic diseases is that the epidemic-disease risk is systemic, meaning that many of those who are insured can suffer losses at the same time. Private-sector insurance companies find it difficult to maintain adequate financial reserves and to obtain sufficient reinsurance capacity (i.e. insurance for the insurance company) when dealing with risks that have systemic characteristics. However, recent developments in capital markets provide opportunities to enlarge the reinsurance capacity (Miranda and Glauber 1997). Partnerships between the public and private sectors may furthermore attract some financial involvement from government.

Some form of public-private partnership is also important when considering prevention measures to reduce the risks of an outbreak. A partnership is, for instance, important to prevent delaying debates about prevention and control strategies; some (additional) control measures may seem cost-reducing at the time they are taken, but they may lead to significantly higher total losses (for instance due to enlargement of export bans). Also, a partnership for risk financing is relevant to reduce moral hazard of governments; many epidemics can either be prevented or magnified by government policies (or lack thereof). Having governments financially responsible for some losses might be incentive for them to put into place appropriate animal-disease control measures (Meuwissen, Van Asseldonk and Huirne 2003).

The described economic analysis should be considered a pilot study; the quality of the country-specific results depends on the quality and completeness of the underlying data. For some member states there are not enough data of sufficient quality to perform such an analysis. Lack of detailed data on the location of animals hampers epidemiological calculations that are needed to further define the effects of regional concentration of animal densities. User-friendly software, linked to sound scientific methods, is now available but their application is - at present - severely limited due to the lack of detailed information that is needed as input to these systems (Wilpshaar et al. 2002).

\section{References}

Hardaker, J.B., Huirne, R.B.M. and Anderson, J.R., 1997. Coping with risk in agriculture. $\mathrm{CAB}$ International, Wallingford.

Homepage DG SANCO. European Commission Health and Consumer Protection Directorate-General (DG SANCO) (website). [http://www.europa.eu.int/comm/dgs/health_consumer/index_en.htm]

Homepage LNV. Ministerie van Landbouw, Natuur en Voedselkwaliteit (website). [http://www.minlnv.nl]

Horst, H.S., Dijkhuizen, A.A., Huirne, R.B.M., et al., 1999. Monte Carlo simulation of virus introduction into the Netherlands. Preventive Veterinary Medicine, 41 (2/3), 209-229. 
Meuwissen, M.P., Horst, S.H., Huirne, R.B., et al., 1999. A model to estimate the financial consequences of classical swine fever outbreaks: principles and outcomes. Preventive Veterinary Medicine, 42 (3/4), 249-270.

Meuwissen, M.P.M., Horst, H.S., Huirne, R.B.M., et al., 1997. Schade verzekerd!? : een haalbaarheidsstudie naar risico-kwantificering en verzekering van veewetziekten. Wageningen, Landbouwuniversiteit.

Meuwissen, M.P.M., Van Asseldonk, M.A.P.M. and Huirne, R.B.M., 2003. Alternative risk financing instruments for swine epidemics. Agricultural Systems, 75 (2/3), 305-322.

Miranda, M.J. and Glauber, J.W., 1997. Systemic risk, reinsurance, and the failure of crop insurance markets. American Journal of Agricultural Economics, 79 (1), 206-215.

OIE classification of diseases: animal diseases data (website). Office International des Epizootie OIE. [http://www.oie.int/eng/maladies/en_classification.htm]

Tacken, G.M.L., Van Leeuwen, M.G.A., Koole, B., et al., 2003. Ketenconsequenties van de uitbraak van vogelpest. LEI, Den Haag. Rapport LEI no. 6.03.06.

Van Asseldonk, M.A.P.M., Meuwissen, M.P.M. and Huirne, R.B.M., 2004. Riskfinancing strategies to manage epidemic animal disease costs in the UK. Farm Management, 11 (12), 686-697.

Wilpshaar, H., Meuwissen, M.P.M., Tomassen, F.H.M., et al., 2002. Economic decision making to prevent the spread of infectious animal diseases. Proceedings of 20th Conference of the O.I.E. Regional Commission for Europe, September 2002, Finland. 